\title{
Erector Spinae Plane Block for Mastectomy and Breast Flap Reconstructive Surgery: A Three Case Series
}

\author{
Wei Shyan Siow* ${ }^{\circledR}$, Jimmy Guan Cheng Lim, Kwee Lian Woon \\ Department of Anaesthesia and Surgical Intensive Care, Changi General Hospital, Singapore, Singapore \\ Email: *weishyan.siow@mohh.com.sg
}

How to cite this paper: Siow, W.S., Lim, J.G.C. and Woon, K.L. (2020) Erector Spinae Plane Block for Mastectomy and Breast Flap Reconstructive Surgery: A Three Case Series. Open Journal of Anesthesiology, 10, 30-37.

https://doi.org/10.4236/ojanes.2019.101003

Received: December 5, 2019

Accepted: January 13, 2020

Published: January 16, 2020

Copyright $\odot 2020$ by author(s) and Scientific Research Publishing Inc. This work is licensed under the Creative Commons Attribution International License (CC BY 4.0).

http://creativecommons.org/licenses/by/4.0/

\begin{abstract}
Uncontrolled pain after breast surgery can have early to chronic repercussions. The repertoire of pre-emptive opioid-sparing analgesic options includes regional blocks such as paravertebral blocks to myofascial blocks and more recently the Erector Spinae (ESP) block. Case 1 demonstrates the ESP block as an easy and conveniently performed post-operative rescue block for a patient who still experienced uncontrolled pain despite a combination of myofascial blocks and systemic analgesics. Case 2 and 3 demonstrate the advantage of providing an extensive coverage of surgical field in breast reconstruction surgery covering variable donor sites. It was due to the extent of coverage, that allowed the placement of ESP block catheter distantly without interrupting the surgical site. Post operative prolongation of pain relief was also successful by titrating analgesia via intermittent boluses. In our case series, the ESP block consistently and safely provided satisfactory pain relief for breast reconstruction surgery. It can be a viable option for peri-operative analgesia compared to other more invasive or less extensive alternatives.
\end{abstract}

\section{Keywords}

Erector Spinae Block, Analgesia, Mastectomy, Breast Reconstructive Surgery, Flap

\section{Introduction}

It has been estimated that the incidence of chronic post-operative pain ranges from 25 to 60 percent among female population undergoing breast surgery with post-operative pain scores as a main predictor [1].

Fascial or myofascial blocks have been popular with the widespread use of ul- 
trasound. Multimodal analgesics with regional anaesthesia techniques with pectoral nerve block, serratus plane block and paravertebral blocks have traditionally been used for breast surgery.

An erector spinae plane block first reported in 2016 [2], has been shown to block the dorsal rami (anesthesia) and provide analgesia to the ventral rami of the thoracic and lumbar region [3].

We describe our use of the erector spinae plane block in three patients who underwent elective breast reconstructive surgeries involving different types of flaps: the lateral intercostal perforator artery flap, latissimus dorsi and free transverse upper gracilis.

\section{Case Report}

\section{Case 1}

We present a 54-year-old lady $(157 \mathrm{~cm}, 56 \mathrm{~kg})$ who underwent a left mastectomy with lateral intercostal perforator artery flap reconstruction in the same setting. A pectoral nerve block I and II were performed as described by Blanco. A Serratus plane block was also performed, aimed to block the long thoracic nerve, and previously described to be effective for post thoracotomy pain. The blocks were performed after induction of general anaesthesia and insertion of a supraglottic airway (maintained with Nitrous oxide and Desflurane). Intraoperative analgesia included Fentanyl $100 \mathrm{mcg}$, Ketamine $25 \mathrm{mg}$ and Oxycodone 3 $\mathrm{mg}$ at the end of surgery (185 mins). The patient had a pain score of 7/10 over the surgical site 4 hours after the blocks. As the anterior part of the chest wall was bandaged, a unilateral erector spinae block without catheter was offered to her. It was performed over T4 via an $18 \mathrm{~g}$ Tuohy needle with $20 \mathrm{ml}$ of $0.5 \%$ Ropivacaine with 1:200,000 adrenaline added as injectate into the plane (Figure 1). Ultrasound scan of the spread of local anaesthetic agent from T1 to L1 within the plane below the erector spinae muscle was visualised. The patient had a corresponding loss of sensation to cold from T1 to L1. Her pain score decreased to $0 / 10$ within 5 minutes of the block.

\section{Case 2}

A 51-year-old lady $(156 \mathrm{~cm}, 53 \mathrm{~kg})$ who had right breast cancer underwent a right breast skin sparing mastectomy, axillary sentinel lymph node biopsy and latissimus dorsi flap reconstruction with additional gel implant under the flap in the same setting. She also had a left breast lump which was excised and sent for frozen section. A pectoral nerve block was avoided with concerns of an infection risk to the implant being so proximal to the surgical plane. We also avoided a paravertebral catheter at T4-T5 level which could interfere with the latissimus dorsi flap. For this reason, an ESP catheter block was performed at T3 level on the right side whilst local anaesthetic infiltration by the surgeon was provided for the left breast. For the ESP block, a bolus dose of $25 \mathrm{ml}$ of $0.4 \%$ Ropivacaine with 1:200,000 adrenaline was given into the erector spinae plane before catheter insertion. The catheter was anchored at $9 \mathrm{~cm}$ with $4 \mathrm{~cm}$ in space (Figure 2). The 
patient was then induced and an endotracheal tube was inserted for the operation which lasted 6 hours. Intraoperative analgesia included 2 doses of paracetamol $1 \mathrm{~g}$, Parecoxib $40 \mathrm{mg}$, Fentanyl $100 \mathrm{mcg}$, target controlled infusion of Remifentanil (effect site concentration of 0.3 to $1 \mathrm{ng} / \mathrm{ml}$ ), Oxycodone $10 \mathrm{mg}$ and Ketamine $40 \mathrm{mg}$. Dexamethasone $8 \mathrm{mg}$ was given as part of multimodal analgesia and as an antiemetic. A further bolus of $0.5 \%$ Ropivacaine $20 \mathrm{ml}$ with adrenaline 1:200,000 was given at the end of surgery. 0.5\%. 12 hours after (2 am), the patient received a dose of Oxycodone $5 \mathrm{mg}$ with a pain score of 7/10. The next morning, she subsequently required a top up of $0.5 \%$ Ropivacaine 20 $\mathrm{ml}$ and 1:200,000 adrenaline which effectively relieved her pain score of 6/10 to $0 / 10$. This was associated with a loss of cold sensation from T4 to L5 which adequately covered the surgical site (Figure 3 ). The catheter was subsequently removed and she was discharged on the same day with oral Oxycodone $5 \mathrm{mg}$, Etoricoxib $120 \mathrm{mg}$ and paracetamol $1 \mathrm{~g}$.

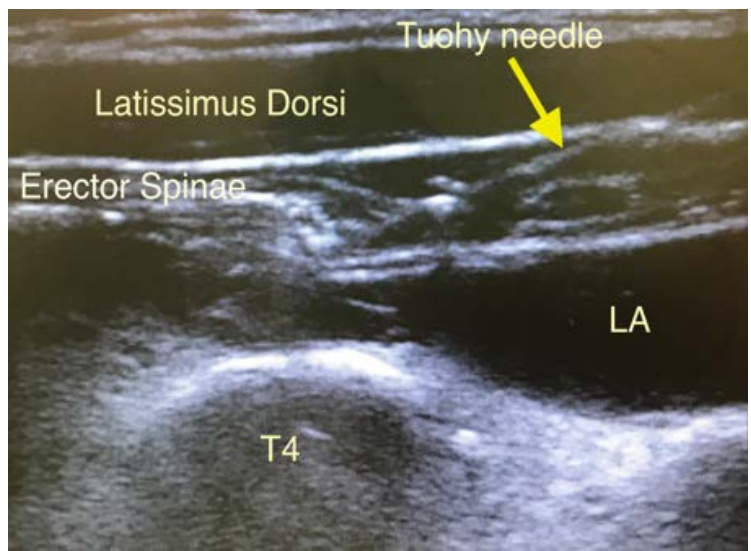

Figure 1. Ultrasound scan of erector spinae plane block with spread of local anaesthesia (LA) in the plane between T4 transverse process and erector spinae muscle. The arrow indicates the Touhy needle passing through the latissimus dorsi and erector spinae muscle to reach this plane.

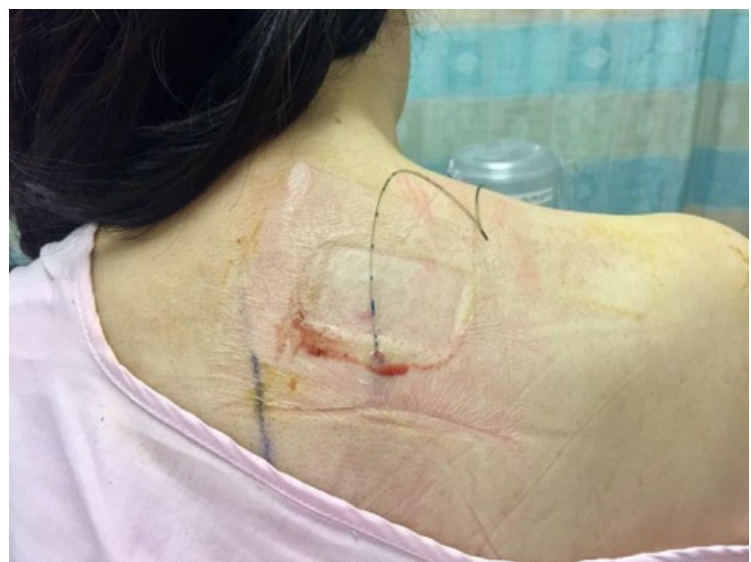

Figure 2. A right sided erector spinae plane block catheter inserted at T3 level pre-induction. This catheter site was high enough not to interfere with the incision for latissimus dorsi flap harvesting. 


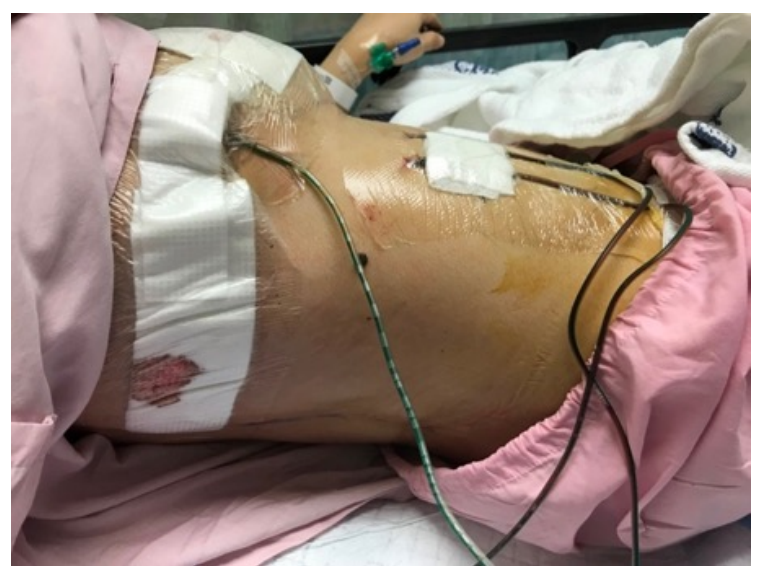

Figure 3. Case 2 describes a patient who underwent a right breast skin sparing mastectomy, axillary sentinel lymph node biopsy and latissimus dorsi flap reconstruction with additional gel implant under flap. This photo shows the extensive surgical and drain sites. A right sided erector spinae block catheter provided extensive coverage for this.

\section{Case 3}

A 36-year-old lady $(159 \mathrm{~cm}, 52 \mathrm{~kg})$ underwent excision of right nipple, removal of implant and pectoralis major fascia and left free transverse upper gracilis flap reconstruction for recurrence of a high grade ductal carcinoma in situ. She was offered bilateral erector spinae plane blocks with catheters sited at T4 (right) and T12 (left) performed after induction for patient's comfort. A bolus of $20 \mathrm{ml}$ of $0.5 \%$ Ropivacaine was given via Tuohy needle before catheter insertion. $2 \mathrm{~cm}$ of the catheter was left in space and anchored at $10 \mathrm{~cm}$ at skin. The operation lasted 10 - 11 hours. Intraoperative analgesia included Fentanyl 100 mcg, Morphine $10 \mathrm{mg}$, paracetamol $1 \mathrm{~g}$ and Parecoxib $40 \mathrm{mg}$. Immediate post-operative pain scores were $0 / 10$ at rest and $1 / 10$ with coughing. Gradually the next day, the pain increased to $5 / 10$. She refused oral analgesia initially and the pain was worse at the donor site. Further boluses of $10 \mathrm{ml} 0.5 \%$ Ropivacaine was given at each side and the patient subsequently reported a reduction of pain score to $0 / 10$ at rest and 1-2/10 with coughing and movement. She was encouraged to take her oral analgesics if the pain worsened. The catheters were subsequently removed as the patient was tolerating the pain well with oral analgesics (Table 1).

\section{Discussion}

In the early phase, an estimated $40 \%$ of patients after breast cancer surgery report moderate to severe pain [4]. Uncontrolled pain may exacerbate sympathetic activity which compromises free flap survival. Other repercussions may include increased risk of pulmonary and immune function impairment, ileus, thromboembolism, myocardial infarction, and prolonged hospital stay [5]. Up to $25 \%$ to $60 \%$ of breast surgery patients may also develop chronic pain syndromes in the long run [1]. Therefore adopting a multi-modal pre-emptive analgesic strategy is paramount. 
Table 1. Summary of the three cases.

\begin{tabular}{|c|c|c|c|c|}
\hline Case & Patient & Operation & Erector spinae block & What we demonstrate \\
\hline 1 & $\begin{array}{l}54 \text { year } \\
\text { old } \\
\text { Chinese } \\
\text { female }\end{array}$ & $\begin{array}{l}\text { Left mastectomy with } \\
\text { lateral intercostal } \\
\text { perforator artery flap } \\
\text { reconstruction }\end{array}$ & $\begin{array}{l}\text { Indication: } \\
\text { Patient developed post operative moderate } \\
\text { to severe pain despite having a pectoral } \\
\text { nerve and serratus plane block, in addition } \\
\text { to fentanyl, ketamine and oxycodone. } \\
\text { Block performed: } \\
\text { Post operative single shot unilateral ESP } \\
\text { block at T4 level }\end{array}$ & $\begin{array}{l}\text { A single shot ESP block can be an effective rescue } \\
\text { analgesia block as shown by immediate and effective pain } \\
\text { relief with widespread coverage from } \mathrm{T} 1 \text { to } \mathrm{L} 1 \text {. } \\
\text { Access for injection was not an issue as we could perform } \\
\text { it away from the anterior surgical site and dressings, and } \\
\text { easily in a lateral position. }\end{array}$ \\
\hline 2 & $\begin{array}{l}51 \text { year } \\
\text { old } \\
\text { Chinese } \\
\text { female }\end{array}$ & $\begin{array}{l}\text { Right mastectomy, } \\
\text { axillary sentinel lymph } \\
\text { node biopsy and latissimus } \\
\text { dorsi flap reconstruction } \\
\text { with additional gel implant } \\
\text { under flap } \\
\text { Left breast lump excision }\end{array}$ & $\begin{array}{l}\text { Indication: } \\
\text { To provide intra and post operative } \\
\text { analgesia. } \\
\text { Block performed: } \\
\text { Pre-induction unilateral sided ESP } \\
\text { catheter performed at T3 level }\end{array}$ & $\begin{array}{l}\text { An ESP catheter can be easily performed in an awake } \\
\text { patient pre-induction. } \\
\text { The ESP catheter could also be placed remotely from the } \\
\text { surgical site, with less risk of interference and infection of } \\
\text { surgical site which was the concern with a paravertebral } \\
\text { or pectoral nerve block respectively. } \\
\text { The ESP block provided extensive coverage from T4-L5. }\end{array}$ \\
\hline 3 & $\begin{array}{l}36 \text { year } \\
\text { old } \\
\text { Chinese } \\
\text { female }\end{array}$ & $\begin{array}{l}\text { Excision of right nipple } \\
\text { Removal of implant and } \\
\text { pectoralis major fascia and } \\
\text { left free transverse upper } \\
\text { gracilis flap reconstruction }\end{array}$ & $\begin{array}{l}\text { Indication: } \\
\text { To provide intra and post operative } \\
\text { analgesia. } \\
\text { ESP Block performed: } \\
\text { Post-induction bilateral ESP with catheters } \\
\text { at level T4 (right) and T12 (left) }\end{array}$ & $\begin{array}{l}\text { We demonstrated widespread coverage of anaesthesia } \\
\text { extending as far down as the thigh especially if placement } \\
\text { was low enough (T12). } \\
\text { Like in case 2, with catheter(s) in-situ, it was versatile to } \\
\text { s titrate intermittent boluses of ropivacaine to prolong } \\
\text { satisfactory analgesia. }\end{array}$ \\
\hline
\end{tabular}

Regional analgesia is increasingly becoming a significant part of the multi-modal analgesic strategy. With the variable donor site involved in breast reconstruction, an armamentarium of blocks has found their place in breast surgery, ranging from paravertebral blocks being the gold standard, to a combination of fascial or myofascial blocks e.g. pectoral nerve block I, II and serratus anterior plane block, and now more recently, the erector spinae plane block as an indirect access to the paravertebral space.

A pooled review by Tsui et al. found 85 publications of 242 reported cases of ESP blocks used perioperatively between 2016 and 2018. The majority of cases used single shot ESP blocks compared to intermittent boluses or continuous infusion. The majority of ESP block was performed at the thoracic level compared to cervical or lumbar region. $90.9 \%$ reported use of multimodal analgesia in addition to the ESP block. $76 \%$ of the cases reported a reduction in opioid usage. [6].

Particular to breast cancer surgery, the effectiveness of ESP for analgesia is demonstrated in a randomized controlled study comparing ESP block vs no intervention as control. Morphine consumption reflected by patient controlled analgesia device was consistently and significantly reduced at all studied time intervals for patients who underwent ESP blockade [7].

The use of ESP block to provide surgical anaesthesia for breast surgery has been reported once so far. This was limited to a radical mastectomy without pectoralis muscle resection and there was no reconstruction involved [8].

Our case series demonstrates the following advantages in using an ESP block as part of a multimodal analgesic strategy for breast reconstruction surgery: 
The ESP block is easy to perform with a well-defined sonographic end-point an injection between the bony transverse process and erector spinae muscle. Therefore, it can be performed easily in patients awake or under general anaesthesia. Being more superficial, it has less risk of pneumothorax as compared to paravertebral block and also less risk of neuraxial injury or haemodynamic instability due to sympathetic blockade as compared to intrathecal or epidural blocks.

The ESP block is also quick to provide relief and has a role in being a post-operative analgesic rescue in case 1 . In case 2 and 3, inserting catheters had the advantage of extending pain relief intra to post operatively via intermittent boluses of local anaesthetic.

It has an extensive coverage. Based on cadaveric studies guided by magnetic resonance imaging and anatomical dissection, it has not only been shown to spread to the epidural and neural foraminal spaces, but also extensively over the intercostal spaces with widespread cranio-caudal distribution along the paraspinal muscles [9] allowing indirect access to the paravertebral space. This extensive coverage is its primary advantage over other blocks it not only covers the anterior and lateral chest wall (like the pectoral nerve II and serratus nerve block), but also the posterior chest wall and as low as the abdomen and groin. An erector spinae plane block injection as low as T12 covered the donor site for the left thigh as shown in case 3.

It is due to the vast extent of coverage, that the catheters could be placed remote enough from the surgery. In case 1, the site of injection posteriorly had relatively preserved anatomy post-operatively. As in case 2 and 3, the surgeons preferred ESP block over paravertebral or pectoral nerve block as they did not want any interference or infection at surgical site respectively.

However the potential limitations of ESP block in breast surgery may include the following-Firstly, being more superficial does not guarantee safety and vigilance to safe needling skills is still paramount. Secondly, a potential drawback of a unilateral erector spinae plane block is that the medial breast may not be covered effectively as this region may have contralateral innervation. Thirdly, we found that the quality and density of the erector spinae plane block was more variable than what we would have otherwise observed in a paravertebral block.

Therefore, although the erector spinae plane block seems favourable for many reasons, there is still not one myofascial block that is the panacea that effectively covers the whole breast and axilla. Therefore a combination with other blocks depending on the site of incision and extent of surgical resection is advocated [10].

With a paucity of high quality evidence regarding ESP blocks in breast reconstruction surgery, we look to further research on how the use of additives, variations in doses, volume, injection sites and positioning influence the nature of the block and toxicity. This can help define duration and quality of analgesia and standardize dosing regimes. Another important outcome is the follow up of such 
patients long term to study the effect of these blocks as preventive techniques against chronic pain.

\section{Conclusion}

In conclusion, our case series demonstrates the use of ESP block for various breast reconstructive surgeries as a viable regional analgesic option which is safe, effective, extensive in coverage and easy to perform. However, it is not without limitations.

\section{Ethics Approval and Consent to Participate}

Not applicable.

\section{Consent for Publication}

Informed consent was obtained for all patients.

\section{Availability of Data and Materials}

Not applicable.

Data sharing is not applicable to this article as no datasets were generated or analysed during the current study.

\section{Funding}

There is no declared need for funding for this report.

\section{Authors Contribution}

JCGL and KLW recruited, consented and managed the patients. WSS, JCGL and KLW wrote the manuscript.

All authors read and approved the manuscript.

\section{Acknowledgements}

Not applicable.

\section{Conflicts of Interest}

The authors declare no conflicts of interest regarding the publication of this paper.

\section{References}

[1] Gärtner, R., Jensen, M.B., Nielsen, J., Ewertz, M., Kroman, N., Kehlet, H., et al. (2009) Prevalence of and Factors Associated with Persistent Pain Following Breast Cancer Surgery. JAMA, 302, 1985-1992. https://doi.org/10.1001/jama.2009.1568

[2] Forero, M., Rajarathinam, M., Adhikary, S. and Chin, K.J. (2017) Continuous Erector Spinae Plane Block for Rescue Analgesia in Thoracotomy after Epidural Failure: A Case Report. A \& A Case Reports, 8, 254-256. https://doi.org/10.1213/XAA.0000000000000478 
[3] Chin, K.J., Adhikary, S., Sarwani, N. and Forero, M. (2017) The Analgesic Efficacy of Pre-Operative Bilateral Erector Spinae Plane (ESP) Blocks in Patients Having Ventral Hernia Repair. Anaesthesia, 72, 452-460. https://doi.org/10.1111/anae.13814

[4] Poleshuck, E.L., Katz, J., Andrus, C.H., Hogan, L.A., Jung, B.F., Kulick, D.I., et al. (2006) Risk Factors for Chronic Pain Following Breast Cancer Surgery: A Prospective Study. Journal of Pain, 7, 626-634. https://doi.org/10.1016/j.jpain.2006.02.007

[5] Joshi, G.P. and Ogunnaike, B.O. (2005) Consequences of Inadequate Postoperative Pain Relief and Chronic Persistent Postoperative Pain. Anesthesiology Clinics of North America, 23, 21-36. https://doi.org/10.1016/j.atc.2004.11.013

[6] Tsui, B.C.H., Fonseca, A., Munshey, F., McFadyen, G. and Caruso, T.J. (2019) The Erector Spinae Plane (ESP) Block: A Pooled Review of 242 Cases. Journal of Clinical Anesthesia, 53, 29-34. https://doi.org/10.1016/j.jclinane.2018.09.036

[7] Gürkan, Y., Aksu, C., Kuş, A., Yörükoğlu, U.H. and Kılıç, C.T. (2018) Ultrasound Guided Erector Spinae Plane Block Reduces Postoperative Opioid Consumption Following Breast Surgery: A Randomized Controlled Study. Journal of Clinical Anesthesia, 50, 65-68. https://doi.org/10.1016/j.jclinane.2018.06.033

[8] Kimachi, P.P., Martins, E.G., Peng, P. and Forero, M. (2018) The Erector Spinae Plane Block Provides Complete Surgical Anesthesia in Breast Surgery: A Case Report. A \& A Practice, 11, 186-188. https://doi.org/10.1213/XAA.0000000000000777

[9] Sanjib, D.A., Stephanie, B., Hector, L., Chin, K.J., et al. (2018) Erector Spinae Plane Block versus Retrolaminar Block. A Magnetic Resonance Imaging and Anatomical Study. Regional Anaesthesia and Acute Pain, 43, 756-762.

[10] Rakesh, G., Swati, B. and Saurabh, V. (2018) Newer Regional Analgesia Interventions (Fascial Plane Blocks) for Breast Surgeries: Review of Literature. Indian Journal of Anaesthesia, 62, 254-262. https://doi.org/10.4103/ija.IJA $46 \quad 18$

\section{List of Abbreviations}

PEC: pectoral nerve

ESP: Erector Spinae Plane

SAP: Serratus plane

PVB: paravertebral blocks 